\title{
BLOOD AND URINE CONCENTRATIONS OF VASCULAR ENDOTHELIAL GROWTH FACTOR IN DOGS WITH TUMOURS
}

\author{
TS. T. HRISTOV \& R. G. BINEV \\ Department of Internal Non-infections Diseases, Faculty of Veterinary \\ Medicine, Trakia University, Stara Zagora, Bulgaria
}

\begin{abstract}
Summary
Hristov, Ts. T. \& R. G. Binev, 2021. Blood and urine concentrations of vascular endothelial growth factor in dogs with tumours. Bulg. J. Vet. Med., 24, No 4, 596-600.

Vascular endothelial growth factor (VEGF) is a potent mitogen for vascular endothelial cells. It improves cell survival, stimulates angiogenesis, inhibits cell apoptosis and strongly enhances vascular permeability. In this study, VEGF concentrations were assayed in blood plasma and urine of 22 dogs with neoplasms (lymphosarcoma, splenic haemangiosarcoma and mammary gland carcinoma) and in 7 healthy dogs by means of ELISA. Average blood plasma VEGF in control dogs was $42.13 \pm 7.37$ $\mathrm{pg} / \mathrm{mL}$, while in dogs with lymphoma $-113.35 \pm 16.48 \mathrm{pg} / \mathrm{mL}$, in dogs with haemangiosarcoma $154.85 \pm 48.46 \mathrm{pg} / \mathrm{mL}$ and in dogs with mammary gland carcinoma $-104.31 \pm 12.45 \mathrm{pg} / \mathrm{mL}$. Urine VEGF concentrations in dogs affected with lymphosarcoma were $712.42 \pm 233.85 \mathrm{ng} / \mathrm{g} \mathrm{uCr}$, in animals with haemangiosarcoma - $223.50 \pm 262.33 \mathrm{ng} / \mathrm{g} \mathrm{uCr}$ and in those with mammary carcinoma: $1053.92 \pm 311.63 \mathrm{ng} / \mathrm{g} \mathrm{uCr}$. In healthy controls average urine VEGF was $310.11 \pm 28.11 \mathrm{ng} / \mathrm{g} \mathrm{uCr}$.
\end{abstract}

Key words: dogs, blood plasma, tumours, urine, vascular endothelial growth factor

The vascular endothelial growth factor (VEGF) is a glycoprotein with key role in physiological and pathological angiogenesis. It suppresses several mechanisms of apoptosis and thus promotes endothelial cell survival (Ferrara, 2004). VEGF has a potent beneficial effect on vascular permeability and transvascular molecular transport (Takano et al., 2011). Evidence about its role in genesis of various types of tumours was provided (Stefanou et al., 2004; Ghasemi et al., 2012; Zhao et al., 2012). Increased VEGF expression in cancer cells initiates tumour neovascularisation (Bergers \& Benjamin, 2003). Substantial increase in blood VEGF levels was reported in mammary gland tumours (Kato et al., 2007), hepatocellular carcinoma (Poon et al., 2003), oral melanoma (Taylor et al., 2007), canine lymphosarcoma (Gentilini et al., 2005), skin malignancies (Sobczyńska-Rak, 2009). Apart in blood, high VEGF concentrations were reported in urine of human patients with prostate gland tumours (Bok et al., 2001) and renal carcinoma (Chang et al., 2001) 
as well as in urinary bladder carcinoma in dogs (Mohammed et al., 2002).

The lack of comparative studies on blood plasma and urine VEGF concentrations in dogs with oncological diseases that do not affect the urinary system, was the incentive for this study.

The investigation was carried out with twenty nine dogs referred to the Small Animal Clinic of the Faculty of Veterinary Medicine, Trakia University - Stara Zagora, Bulgaria. They were allotted into four groups:

- Control group of clinically healthy dogs $(n=7)$;

- Group I: dogs with lymphosarcoma $(n=6)$;

- Group II: dogs with splenic haemangiosarcoma $(n=8)$;

- Group III: dogs with mammary gland carcinoma $(\mathrm{n}=8)$.

In all dogs diagnosed with tumours, the diagnoses was histopathologically confirmed.

Blood samples were collected from all animals by venepuncture of $v$. cephalica antebrachii in commercial heparinised tubes. For assay of plasma VEGF concentrations, Quantikine Canine VEGF ELISA (R\&D Systems Inc, Catalog Number CAVE00) was used. Blood plasma was obtained by centrifugation of freshly collected heparinised blood samples (5000 rpm) for $30 \mathrm{~min}$. Plasma was harvested immediately after centrifugation and stored at $-20{ }^{\circ} \mathrm{C}$ until analysis.

Urine VEGF was assayed in first morning urine after centrifugation (1000 $\mathrm{rpm}, 20 \mathrm{~min}$ ) and freezing of the supernatant at $-20{ }^{\circ} \mathrm{C}$ within 4 hours from collection as described by Hayward et al. (2008). Urine VEGF levels were quantitated by means of Quantikine Canine VEGF - ELISA тест (R\&D Systems, Inc, Catalog Number CAVE00). Creatinine in urine samples were determined on automated biochemical analyser Mindray BS120 - China. Due to differences in the rate of diuresis, urine VEGF concentrations were normalised vs urine creatinine levels and presented as ng VEGF/g urinary creatinine (Reid et al., 2012).

Data were statistically processed with Statistica v. 6.1 software (StatSoft Inc., 2002). All data were expressed as means and SEM and submitted to one-way ANOVA. $\mathrm{P}$ values $<0.05$ were assumed to be statistically significant. Pearson's correlation coefficients were calculated by Minitab 18 software (Minitab Company, Pennsylvania, USA).

Table 1 presents blood plasma VEGF $(\mathrm{pg} / \mathrm{mL})$, and urine VEGF in absolute values $(\mathrm{pg} / \mathrm{mL})$ and standardised vs urinary creatinine $(\mathrm{ng} / \mathrm{g} \mathrm{uCr})$. The latter varied within a relatively narrow range: from 196.67 to $414.58 \mathrm{ng} / \mathrm{g} \mathrm{uCr}, 310.11 \pm 28.11$ $\mathrm{ng} / \mathrm{g} \mathrm{uCr}$ on the average. In urine of dogs with tumours, VEGF ( $\mathrm{ng} / \mathrm{g} \mathrm{uCr}$ ) was from 2 to 4 times higher compared to healthy dogs. In Group I, average VEGF was $712.42 \pm 233.85 \mathrm{ng} / \mathrm{g} \mathrm{uCr}$ insignificantly different from controls. The highest value in this group was $1596.23 \mathrm{ng} / \mathrm{g} \mathrm{uCr}$. In dogs with haemangiosarcoma (Group II), the parameter values were the highest with mean concentration of $1223.5 \pm 262.33$ $\mathrm{ng} / \mathrm{g} \mathrm{uCr}(\mathrm{P}<0.01$ vs healthy dogs $)$. The highest individual urine VEGF was in this group $-2656.47 \mathrm{ng} / \mathrm{g}$ uCr. In five $(62.5 \%)$ from all 8 dogs, urinary VEGF levels were $>1100$ (ng/g uCr). Similar tendency was observed in group III, with mean urine VEGF concentration of $1053.92 \pm 311.63$ $\mathrm{ng} / \mathrm{g} \mathrm{uCr}(\mathrm{P}<0.05)$ and highest value in the group of $2285.4 \mathrm{ng} / \mathrm{g} \mathrm{uCr}$.

In the three groups of dogs with tumours, strong positive statistically significant correlation was observed between absolute values of urine VEGF and va- 
Blood and urine concentrations of vascular endothelial growth factor in dogs with tumours

Table 1. Concentrations of vascular endothelial growth factor (VEGF) in blood plasma and urine (absolute values and values standardised vs urinary creatinine) in healthy dogs and dogs affected with lymphosarcoma (Group I), haemangiosarcoma (Group II) and mammary gland carcinoma (Group III). Data are presented as mean \pm SEM

\begin{tabular}{lcccc}
\hline & $\begin{array}{c}\text { Healthy controls } \\
(\mathrm{n}=7)\end{array}$ & $\begin{array}{c}\text { Group I } \\
(\mathrm{n}=6)\end{array}$ & $\begin{array}{c}\text { Group II } \\
(\mathrm{n}=8)\end{array}$ & $\begin{array}{c}\text { Group III } \\
(\mathrm{n}=8)\end{array}$ \\
\hline $\begin{array}{l}\text { Blood plasma } \\
\text { VEGF (pg/mL) }\end{array}$ & $42.13 \pm 7.37$ & $113.35 \pm 16.48$ & $154.85 \pm 48.46$ & $104.31 \pm 12.45$ \\
$\begin{array}{l}\text { Urine VEGF }- \\
(\mathrm{pg} / \mathrm{mL})\end{array}$ & $175.44 \pm 19.87^{* * *}$ & $501.29 \pm 220.96$ & $1125.83 \pm 326.67^{*}$ & $885.31 \pm 296.83^{*}$ \\
$\begin{array}{l}\text { Urine VEGF } \\
(\mathrm{ng} / \mathrm{g} \text { uCr })\end{array}$ & $310.11 \pm 28.11^{+++}$ & $712.42 \pm 233.85^{+}$ & $1223.50 \pm 262.33^{++}$ & $1053.92 \pm 311.63^{++}$ \\
\hline
\end{tabular}

${ }^{*} \mathrm{P}<0.05 ; \quad * * \mathrm{P}<0.01 ; * * * \mathrm{P}<0.001$ vs blood plasma VEGF concentrations; $\quad{ }^{+} \mathrm{P}<0.05, \quad{ }^{++} \mathrm{P}<0.01$, ${ }^{+++} \mathrm{P}<0.001$ vs blood plasma concentrations.

lues, standardised vs urinary creatinine: $\mathrm{r}=0.922(\mathrm{P}=0.003)$ for Group $\mathrm{I}, \mathrm{r}=0.772$ $(\mathrm{P}=0.025)$ for Group II and $\mathrm{r}=0.946$ $(\mathrm{P}=0.000)$ for Group III.

The suggestions for high urinary VEGF levels in tumours of kidneys, urinary bladder or prostate gland are confirmed in human (Chang et al., 2001; Sankhwar et al., 2015) and canine research studies (Mohammed et al., 2002). Various reports indicated that the high VEGF urine concentrations were associated with advanced neoplastic growth in renal carcinoma (Chang et al., 2001) and short survival time in prostate gland tumours (Bok et al., 2001). The studies on urinary VEGF excretion in other tumour types are few, and none were found out in dogs.

In the three groups of dogs with malignancies, urine VEGF was elevated. In the lymphosarcoma group the concentrations were insignificantly different than controls. In dogs with haemangiosarcoma, they were the highest ( $\mathrm{P}<0.01$ vs controls) and intermediate in dogs with mammary gland tumours $(\mathrm{P}<0.05$ compared to healthy dogs). Studies in men with brain and haematological neoplasms demon- strated that the measurement of VEGF in urine could be a marker for presence of malignancy or a post treatment marker (Chan et al., 2004; Smith et al., 2008). Our results confirmed that not only urinary tract tumours lead to high urinary VEGF concentrations.

Individual urine VEGF levels in all groups with neoplasms were several times higher than respective blood plasma concentrations. This is observed both for absolute $(\mathrm{pg} / \mathrm{mL})$, and normalised urine VEGF levels (ng/g uCr). Our data showed that urine VEGF reflected reliably blood concentrations and could be of diagnostic value in different canine malignancies. Also, our study established an exceptionally strong correlation between absolute urine VEGF concentrations and values, normalised vs urinary creatinine. This practically suggest the possibility for direct interpretation of absolute urine VEGF values instead of calculating values standardised with respect to urine creatinine. Further studies will confirm or reject this option.

In conclusion, vascular endothelial growth factor was detected in high concentrations in blood and urine of dogs 
with lymphosarcoma, spleen haemangiosarcoma and mammary gland carcinoma. Its assay in urine could be an easy noninvasive method of diagnosis of malignancies in dogs. The possibility for direct interpretation of urine VEGF levels $(\mathrm{pg} / \mathrm{mL})$, instead of values normalised vs urinary creatinine (ng/g uCr) would speed-up and facilitate the diagnostic algorithm.

\section{REFERENCES}

Bergers, G. \& L. E. Benjamin, 2003. Tumorigenesis and the angiogenic switch. Cancer, 3, 401-410.

Bok, R. A., S. Halabi, D. Fei, C. R. Rodriquez, D. F. Hayes, N. J. Vogelzang, P. Kantoff, M. A. Shuman \& E. J. Small, 2001. Vascular endothelial growth factor and basic fibroblast growth factor urine levels as predictors of outcome in hormonerefractory prostate cancer patients. A Cancer and Leukemia Group B study. Cancer Research, 61, 2533-2536.

Chan, L. W., M. A. Moses, E. Goley, M. Sproull, T. Muanza, C. N. Coleman, W. D. Figg, P. S. Albert, C. Ménard \& K. Camphausen, 2004. Urinary VEGF and MMP levels as predictive markers of 1-year progression-free survival in cancer patients treated with radiation therapy: A longitudinal study of protein kinetics throughout tumor progression and therapy. Journal of Clinical Oncology, 22, 499-506.

Chang, S. G., S.-H. Jeon, S.-J. Lee, J.-M. Choi \& Y.-W. Kim, 2001. Clinical significance of urinary vascular endothelial growth factor and microvessel density in patients with renal cell carcinoma. Urology, 58, 904-908.

Ferrara, N., 2004. Vascular endothelial growth factor: Basic science and clinical progress. Endocrine Reviews, 25, 581-611.

Gentilini, F., C. Calzolari, M. E. Turba, C. Agnoli, D. Fava, M. Forni \& P. F. Bergamini, 2005. Prognostic value of se- rum vascular endothelial growth factor (VEGF) and plasma activity of matrix metalloproteinase (MMP) 2 and 9 in lymphoma-affected dogs. Leukemia Research, 29, 1263-1269.

Ghasemi, M., O. Emadian, F. Naghshvar, A. Bekhradnia, S. Abediankenari, L. Larijani \& R. Moghimpour, 2011. Immunohistochemical expression of vascular endothelial growth factor and its correlation with tumor grade in breast ductal carcinoma. Acta Medica Iranica, 49, 776-779.

Hayward, R. M., M. J. Kirk, M. Sproull, T. Scott, S. Smith, T. Cooley-Zgela, N. S. Crouse, D. E. Citrin \& K. Camphausen, 2008. Post-collection, pre-measurement variables affecting VEGF levels in urine biospecimens. Journal of Cellular and Molecular Medicine, 12, 343-350.

Kato, Y,, K. Asano, T. Mogi, K. Kutara, K. Teshima, K. Edamura, S. Tsumagari, A. Hasegawa \& S. Tanaka, 2007. Clinical significance of circulating vascular endothelial growth factor in dogs with mammary gland tumors. Journal of Veterinary Medical Science, 69, 77-80.

Mohammed, S. I., P. Bennett, B. A. Craig, N. W. Glickman, A. J. Mutsaers, P. W. Snyder, W. R. Widmer, A. E. DeGortari, P. L. Bonney \& D. W. Knapp, 2002. Effects of the cyclooxygenase inhibitor, piroxicam, on tumor response, apoptosis, and angiogenesis in a canine model of human invasive urinary bladder cancer. Cancer Research, 62, 356-358.

Poon, R. T., C. P.-Y. Lau, S.-T. Cheung, W.C. Yu \& S.-T. Fan, 2003. Quantitative correlation of serum levels and tumor expression of vascular endothelial growth factor in patients with hepatocellular carcinoma. Cancer Research, 63, 3121-3126.

Reid, C. N., M. Stevenson, F. Abogunrin, M. W. Ruddock, F. Emmert-Streib, J. V. Lamont \& K. E. Williamson, 2012. Standardization of diagnostic biomarker concentrations in urine: The hematuria caveat. PLoS One, 7, e53354. doi: 10.1371/journal.pone.0053354. 
Sankhwar, M., S. Sankhwar, A. Abhishek \& S. Rajender, 2015. Clinical significance of the VEGF level in urinary bladder carcinoma. Cancer Biomarkers, 15, 349-355.

Smith, E. R., D. Zurakowski, A. Saad, R. Scott \& M. A. Moses, 2008. Urinary biomarkers predict brain tumor presence and response to therapy. Clinical Cancer Research, 14, 2378-2386.

Sobczyńska-Rak, A., 2009. Correlation between plasma VEGF and angiogenesis of skin and subcutaneous tissue cancer in dogs. Bulletin of the Veterinary Institute in Puławy, 53, 503-508.

Stefanou, D., A. Batistatou, S. Kamina, E. Arkoumani, D. J. Papachristou \& N. J. Agnantis, 2004. Expression of vascular endothelial growth factor (VEGF) and association with microvessel density in benign prostatic hyperplasia and prostate cancer. In Vivo, 18, 155-160.

Takano, T., T. Ohyama, A. Kokumoto, R. Satoh \& Ts. Hohdatsu, 2011. Vascular endothelial growth factor (VEGF), produced by feline infectious peritonitis (FIP) virusinfected monocytes and macrophages, induces vascular permeability and effusion in cats with FIP. Virus Research, 158, 161-168.
Taylor, K. H., A. N. Smith, M. Higginbotham, D. D. Schwartz, D. M. Carpenter \& E. M. Whitley, 2007. Expression of vascular endothelial growth factor in canine oral malignant melanoma. Veterinary and Comparative Oncology, 5, 208-218.

Zhao, X., X. Sun \& X. Li, 2012. Expression and clinical significance of STAT3, PSTAT3, and VEGF-C in small cell lung cancer. Asian Pacific Journal of Cancer Prevention, 13, 2873-2877.

Paper received 17.06.2019; accepted for publication 27.09.2019

\section{Correspondence:}

Ts. T. Hristov,

Department of Internal Non-infections

Diseases, Faculty of Veterinary Medicine,

Trakia University,

6000 Stara Zagora, Bulgaria, tel: 0035942699534

e-mail: hristov_vet@abv.bg 